\title{
PENGARUH PERSEPSI KONSUMEN MENGENAI TINGKATAN ARTI \\ MEREK TERHADAP KEPUASAN PELANGGAN DAN LOYALITAS \\ MEREK PADA PRODUK THE BODY SHOP YOGYAKARTA
}

\author{
Dian Irma Aprianti \\ Universitas Widya Gama Mahakam Samarinda \\ me.aprianty@gmail.com
}

\begin{abstract}
The main objective of this study is to test empirically the direct effect of the consumer's on six dimensions of brand level, and direct effect through customes;s satisfiction as intervening variable on brand loyalty.

The primary data of this study was received from customers of the body shop, that collected by field survey, the result show that consumer's perception on six dimensions of brand level had a positive and significant relation to customer's satisfaction and brand loyalty, and by using partial mediating method can be conclude that the costumer's satisfaction works as intervening variable to the relation between consumer's perpection on six dimensions of brand level to brand loyalty. This result indicates that customer's brand loyalty happens as the accumulation of customer's satisfaction.
\end{abstract}

Key world : dimensions of brand level, customer's satisfaction, brand loyalty

\section{Pendahuluan}

\section{A. Latar Belakang}

Perubahan teknologi dan globalisasi yang terjadi saat ini mempunyai pengaruh yang sangat besar terhadap peta persaingan industri di lingkungan lokal. Hal ini dapat kita lihat dengan membanjirnya merek luar di lingkungan industri, sehingga hal ini dapat menambah referensi konsumen dalam memilih produk yang mereka butuhkan.

Peranan merek dalam tingkat persaingan yang sangat tinggi seperti sekarang ini menjadi sangat penting. Merek memberikan kontribusi dalam menciptakan dan menjaga daya saing sebuah produk. Lebih lanjut ketika sudah dikenal luas, mereka akan dihubungkan dengan citra khusus yang mampu memberikan asosiasi tertentu dalam benak konsumennya. Menurut Kotler dan Keller

“ bagi sebagian besar perusahaan, pemberian merek sudah merupakan keharusan, sehingga hampir tidak ada produk yang tidak diberi merek"1

\footnotetext{
${ }^{1}$ Kotler, P. Dan Keller (2006),Marketing Management $12^{\text {th }}$. Upper Saddle River, NJ: Prentice Hall Inc. P.256
} 
Alasan penting untuk mengelola dan mengembangkan merek adalah bahwa merek lebih bermakna daripada sekadar simbol. Merek dapat menjelaskan emosi serta hubungan secara spesifik dengan pelanggannya. Hal ini dapat terjadi karena merek mengandung nilai - nilai yang jauh lebih bermakna daripada atribut fisik.

Dalam jangka panjang loyalitas pelangan menjdi tujuan bagi perencanaan pasar stratejik, selain itu juga dijadikan dasar pengembangan keunggulan kompetitif yang berkelanjutan. Penurunan loyalitas dapat berakibat pada menurunnya perolehan laba yang diakibatkan oleh pelanggan yang membeli pada produk lain dan juga adanya pengurangan pemakaian produk.

\section{B. Rumusan Masalah}

1. Apakah persepsi konsumen mengenai tingkatan arti merek ( atribut, nilai, manfaat, budaya, kepribadian, pemakai ) berpengaruh positif pada loyalitas merek?

2. Apakah persepsi konsumen mengenai tingakatan arti merek berpengaruh positif pada kepuasan pelanggan?

3. Apakah kepuasan konsumen berpengaruh positif pada loyalitas pelanggan?

\section{Landasan Teori}

A. Tingkatan arti merek menurut Kotler dan Keller

\section{A.1. Atribut}

Setiap merek memiliki atribut, dimana atribut ini perlu dikelola dan diciptakan agar konsumen dapat mengatahui dengan pasti atribut - atribut apa saja yang terkandung dalam suatu merek

\section{A.2 Manfaat}

Merek juga memiliki serangkaian manfaat. Konsumen tidak membeli atribut, mereka membeli manfaat. Produsen harus dapat menterjemahkan atribut menjadi manfaat fungsional maupun manfaat emosional.

A.3.Merek juga menyatakan sesuatu tentang nilai bagi produsen. Merek yang memiliki nilai yang tinggi akan dihargai oleh konsumen sebagai merek yang berkelas, sehingga dapat mencerminkan siapa pengguna merek tersebut.a.

\section{A.4 Budaya}

Merek juga mewakili budaya tertentu

\section{A.5 Kepribadian}

Merek juga mewakili kepribadian, yaitu kepribadian bagi para penggunanya. Jadi diharapkan dengan mengguankan merek, kepribadian si pengguna akan tercermin bersamaan dengan merek yang digunakannya. 


\section{A.6. Pemakai}

Merek tersebut menyiratkan jenis konsumen yang membeli atau menggunakan produk tersebut. Itulah sebabnya para pemasar selalu menggunakan analogi orang - orang terkenal untuk penggunaan mereknya. ${ }^{2}$

\section{B. Persepsi Konsumen}

Persepsi adalah proses yang digunakan oleh seorang individu untuk memilih, mengorganisasi, dan menginterprestasikan masukan - masukan informasi yang menciptakan gambaran dunia yang memiliki arti. ${ }^{3}$

\section{Merek}

Merek adalah internalisasi sejumlah kesan yang diterima oleh pelanggan dan konsumen yang mengakibatkan adanya suatu posisi khusus dalam ingatan mereka terhadap manfaat - manfaat emosional dan fungsional yang dirasakan. ${ }^{4}$

\section{Konsep Kepuasan Konsumen}

\section{Gambar 1}

\section{Konsep Kepuasan Konsumen}

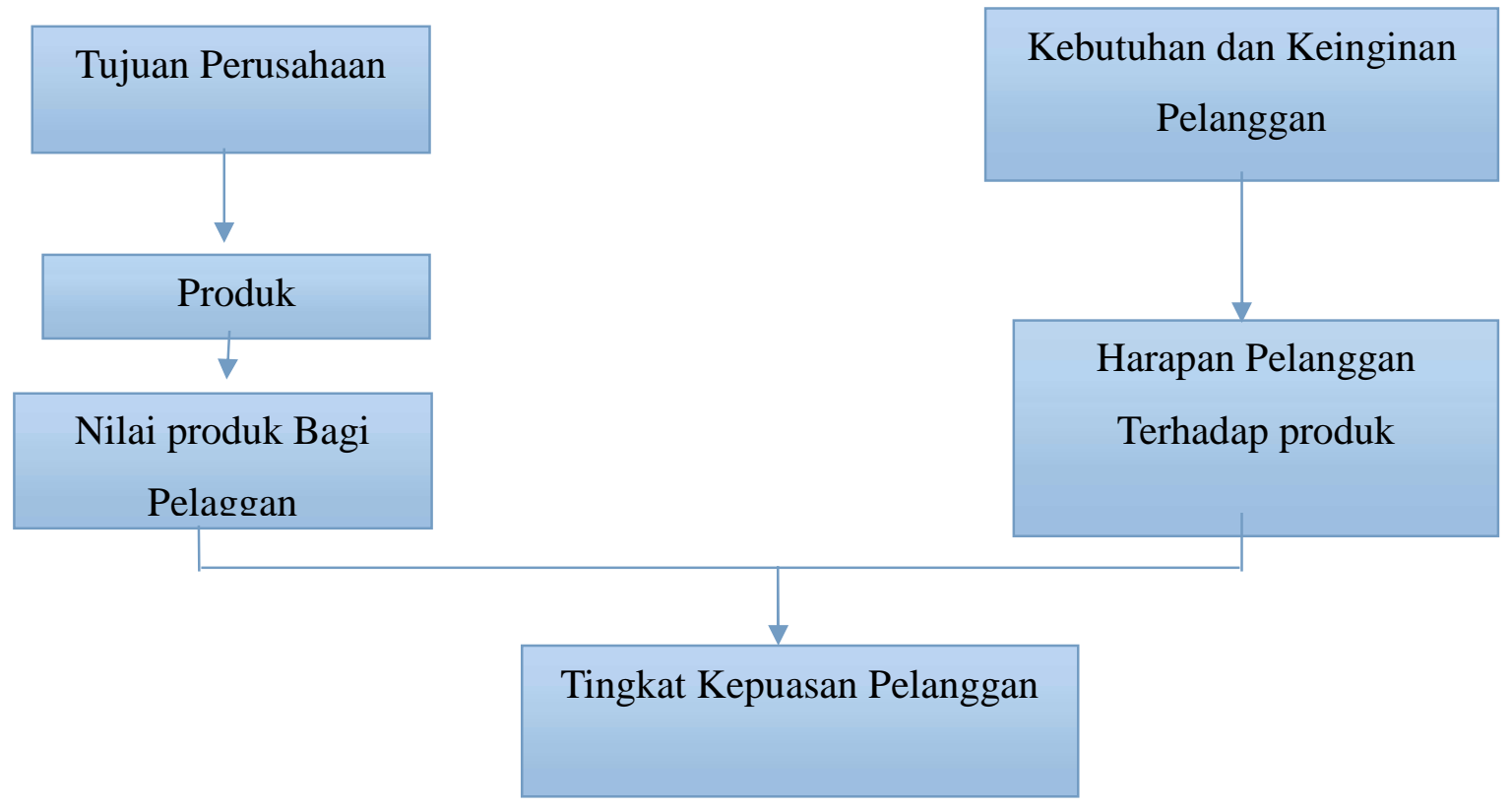

\section{E. Loyalitas Pelanggan}

\footnotetext{
${ }^{2}$ Kotler \& Keller (2003), Marketing Management $11^{\text {th }}$. Upper Saddle River, NJ : Prantice Hall Inc. P.82

${ }^{3}$ Kotler dan Keller (2006), Marketing Management $12^{\text {th }}$. Upper sadle River NJ : Prantice Hall inc. P. 175

${ }^{4}$ Knap dan Chasanah ( 2003 ), Membangun Ekuitas Merek Melalui Brand Personality, Kajian Bisnis STIE Widya Wiwaha Yogyakarta, No 29. H. 99
} 
Menurut Mowen dan Minor dalam Dharmesta "loyalitas merek mempunyai arti kondisi di mana konsumen mempunyai sikap positif terhadap sebuah merek, mempunyai komitmen pada merek tersebut dan bermaksud meneruskan pembeliannya di masa datang",

\section{E. Hipotesis}

Dari rumusan masalah di atas, dapat ditarik hipotesis sebagai berikut :

H1 : Persepsi Konsumen mengenai tingkatan arti merek berpengaruh positif pada loyalitas merek

$\mathrm{H} 2$ : Persepsi konsumen mengenai tingkatan arti merek berpengaruh positif pada kepuasan pelanggan

H3 : Kepuasan Pelanggan berpengaruh positif pada loyalitas merek

H4 : Persepsi konsumen mengenai tingkatan arti merek berpengaruh positif melalui kepuasan pelangan pada loyalitas merek

\section{F. Model Penelitian}

Gambar 2 :

Model Penelitian

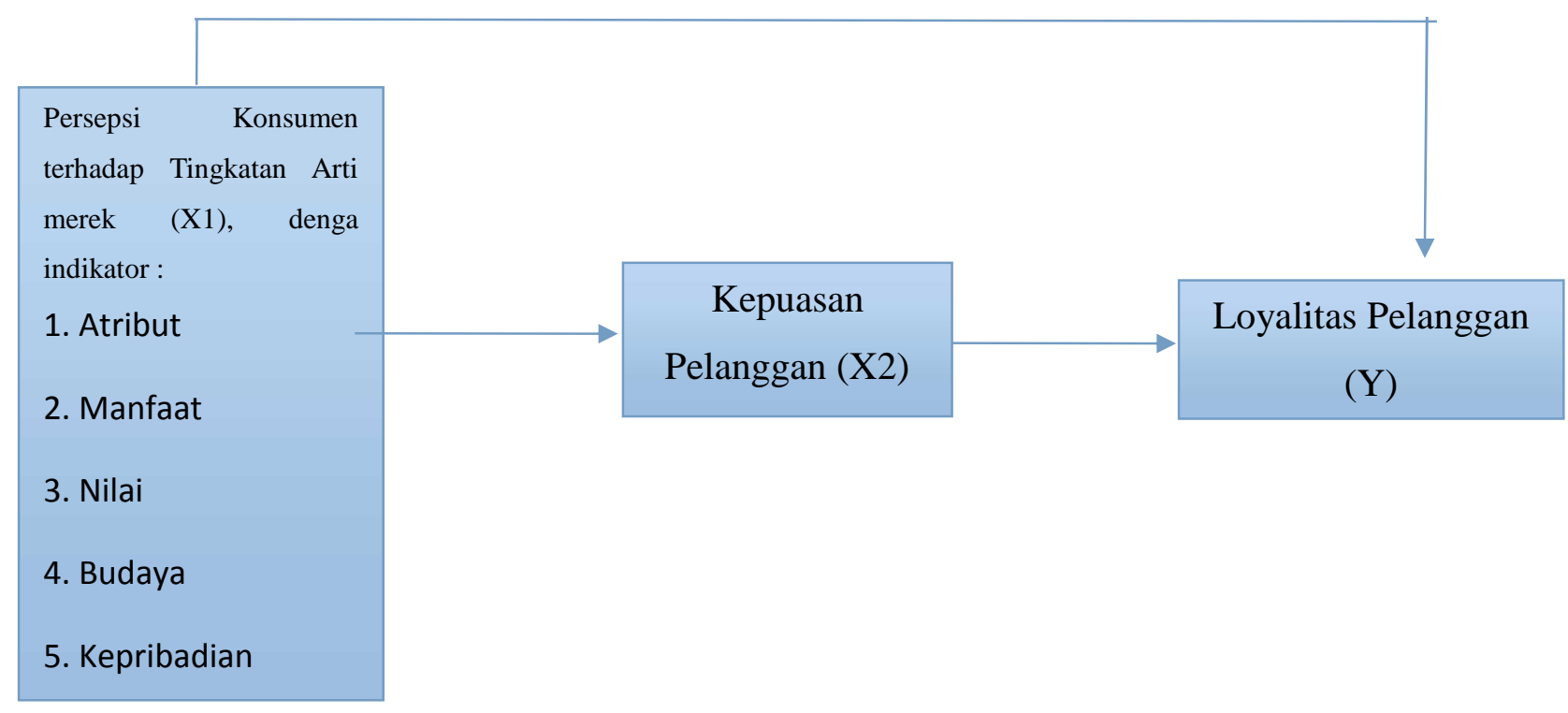

\section{G. Metode Penelitian}

Penelitian ini menggunakan Gerai The Body Shop Yogyakarta sebagai objek penelitian dan masyarakat Yogyakarta berusia 18 - 35 tahun sebagai subjek penelitian dengan metode Purposive Sampling mengambil sample sebanyak 200 orang pelanggan The Body Shop Yogyakarta. Jenis pengumpulan data yaitu Data Primer dengan teknik Penelitian Lapangan dan analisis data menggunakan analisis Regresi Liniear Berganda.

\footnotetext{
${ }^{5}$ Dharmesta (1999), Loyalitas Pelanggan : Sebuah Kajian Konseptual Sebagai Panduan Bagi Peneliti, Jurnal Ekonomi dan Bisnis Indonesia, 14, No 3, H 74.
} 


\section{H. Pembahasan}

Hasil penelitian menunjukkan pengearuh persepsi konumen mengenai tingkatan arti merek terhadap loyalitas merek yang terjadi melalu kepuasan pelanggan. Terjadinya loyalitas merek pada konsumen disebabkan adanya pengaruh kepuasan atau ketidakpuasan dengan merek tersebut dalam hal ini produk merek The Body Shop yang terakumulasi secara terus menerus.

Indikator persepsi yang digunakan dalam penelitin ini adalah : pada tingkatan nilai, indikator yang digunakan adalah penggunaan produk merek The Body Shop memberikan nilai - nilai prestige yang dirasakan yang dirasakan oleh responden. Determinan pertanyaan ini adalah "dengan menggunakan produk merek The Body Shop ada nilai prestige yang saya rsakan" sebesar 3,695, nilai ini mendekati 4, sehingga dapat disimpulkan bahwa sebagian besar jawaban responden setuju bahwa produk merek The Body Shop memberikan nilai prestige yang dirasakan oleh pelanggan.

Pada tingkatan budaya, indikator yang digunakan adalah penggunaan produk merek The Body Shop mencerminkan kelas sosial responden dengan instrumen " Penggunaan merek produk The Body Shop mencerminkan kelas sosial " determinan untuk item ini sebesar 3,675 dan instrumen "Penggunaan produk merek The Body Shop mewakili kultur saya yang simple dan dinamis" determinan untuk item ini sebesar 3,810; nilai - nilai ini mendekati 4, sehingga bisa disimpulkan bahwa sebagian besar responden setuju bahwa penggunaan produk merek The Body Shop mencerminkan kelas sosial mereka dan kultur mereka yang simple dan dinamis.

Pada tingkatan kepribadian, indikator yang digunakan adalah penggunaan produk merek The Body Shop yang mencerminkan kepedulian responden terhadap kecantikan yang alami terwakili oleh instrumen " Dengan menggunakan produk merek The Body Shop maka hal ini mencerminkan diri saya yang peduli dengan kacantikan alami" determinan untuk item ini sebesar 3,79 dan Kepedulian mereka pada lingkungan sosial yang terwakili oleh instrumen " Dengan menggunakan produk merek The Body Shop mencerminkan diri saya yang peduli dengan lingkungan " determinan untuk item ini sebesar 3,70. Masing - masing nilai ini mendekati 4, sehingga dapat disimpulkan bahwa sebagian besar responden setuju bahwa penggunaan produk merek The Body Shop mencerminkan kepedulian mereka terhadap kecantikan alami dan juga pada lingkungan sosial.

Tingakatan mereka yang terakhir yaitu pemakai, indikator yang digunakan adalah penggunaan produk merek The Body Shop menunjukkan posisi responden yang sudah merasa berada pada siklus sukses dalam hidup mereka terwakili oleh instrumen "Dengan menggunakan produk merek The Body Shop maka secara tidak langsung saya sudah merasa berada pada siklus sukses dalam hidup saya” dengan determinan pada item ini sebesar 3,61 dan indikator penggunaan produk merek The Body Shop dengan kemapanan terwakili oleh instrumen "Saya menggunakan produk merek The Body Shop karena saya sudah merasa mapan secara ekonomi” dengan determinan sebesar 3,78, sedangkan indikator bahwa penggunaan produk merek ini sesuai dengan gaya hidup mereka terwakili oleh instrumen " saya menggunakan produk merek The Body Shop karena produk ini sesuai dengan gaya hidup saya " sebesar 3,765. Nilai - nilai ini mendekati 4, sehingga dapat disimpulkan bahwa sebagian besar responden setuju bahwa penggunaan produk merek The Body Shop menunjukkan posisi responden yang sudah merasa beada pada siklus sukses dalam hidup mereka, merasa mapan dalam ekonomi, dan penggunaan produk merek ini juga sesuai dengan gaya hidup mereka. 
Kesemua tingkatan merek ini menunjukkan bahwa merek mempunyai simbol yang kompleks. Jika suatu perusahaan memperlakukan merek hanya sebagai nama maka perusahaan tersebut tidak melihat tujuan merek sebenarnya. Tantangan dalam memberikan merek adalah untuk mengembangkan pengertian yang mendalam atas nama merek tersebut.

Dari jawaban - jawaban responden terlihat bahwa sebagian besar pelanggan produk merek the Body Shop lebih senderung untuk melihat dimensi merek yang bersifat non fisik, seperti dimensi nilai, budaya, kepribadian dan pemakai. Sedangkan dimensi yang bersifat Physical seperti dimensi atribut dan manfaat dalam penelitian ini tidak menjadi salah satu aspek yng membuat mereka loyal dan terus menerus menggunakan produk merek The Body Shop.

Dari hasil perhitungan regresi secara serentak, maka hubungan antara persepsi konsumen mengenai tingkatan arti merek pada loyalitas merek nilai signifikansi atau probabilitas $>(0,05)$ dimana total loyalitas tidak dipengaruhi oleh total persepsi karena hasilnya signifikansi yaitu sebesar 0,89 , tetapi total loyalitas dipengaruhi oleh total kepuasan sehingga dapat disimpulkan bahawa kepuasan sebagai variabel intevening.

Bentuk loyalitas yang didapat adalah bahwa mereka akan melakukan pembelian ulang atas produk merek The Body Shop.

\section{Kesimpulan Dan Saran}

Penelitian ini dilakukan untuk menganalisis pengaruh persepsi konsumen mengenai tingkatan arti merek pada loyalitas merek dengan menggunakan kepuasan pelanggan sebagai variabel intervening. Penelitian ini dilakukan dengan mengambil objek penelitian produk merek The Body shop dengan jumlah responden sebanyak 200 orang. Responden yang dipilih dalam penelitian ini adalah responden yang pernah menggunakan produk merek The Body Shop. Pengumpulan data dilakukan dengan cara menyebar kuesioner pada responden.

Hasil penelitian ini menunjukkan bahwa persepsi konsumen mengenai tingkatan arti merek melalui kepuasan pelanggan berpengaruh positif pada loyalitas merek, hasil penelitian ini mendukung hasil penelitian sebelumnya yang menyatakan bahwa kepuasan pelanggan merupakan variabel intervening dalam hubungan antara persepsi mengenai tingkatan arti merek pada loyalitas merek. Kesimpulan ini didapat dengan melihat hasil signifikansi dari uji yang dilakukan terhadap $\mathrm{H} 1, \mathrm{H} 2, \mathrm{H} 3$ yang merupakan pengujian hubungan antar variabel yang diuji secara parsial.

Selain itu, persepsi konsumen mengenai tingkatan arti merek menunjukkan adanya hubungan yang kuat dalam arti mereka tidak sekedar loyal pada sisi atribut saja tetapi lebih pada tingkatan yang lebih tinggi atau loyal secara emosional. Ini ditunjukkan dengan nilai validitas yang lebih baik pada tingkatan nilai, budaya, kepribadian dan pemakai.

\section{Saran}

Berdasarkan kesimpulan yang tekah diperoleh dalam penelitian ini, maka disampaikan saran yang patut diperhatikan oleh pihak manajemen The Body Shop Yogyakarta dalam meningkatkan kepuasan pelanggan dan loyalitas pelanggan melalui pemahaman mengenai tingkatan arti merek mana mayoritas pelanggan itu berada. Dari hasil analisis dilihat bahwa The Body Shop lebih fokus pada untuk 
membangun nilai - nilai pertukaran berupa berdagangan yang adil, sehingga kurang memperhatikan sisi atribut yang dapat digunakan untuk menarik pelanggan potensial, karena tidak semua calon pelanggan mengetahui misi perdagangan yang diemban The Body Shop. Untuk itu menurut penulis, The Body Shop juga harus lebih memperhatikan atribut merek seperti kemasan yang dibuat menarik, aroma yang dapat bersaing dengan produk merek lain.

Diharapkan pelanggan lebih tertarik pada atribut dan manfaat yang ditawarkan The Body Shop , tanpa mengabaikan misi perdagangan yang diemban The Body Shop.

\section{Daftar Pustaka}

Aaker, David A (1996), Building Strong Brands, New York: The Press

Anggraini, Yunita (2001) “ Dampak Merek Asing pada Persepsi Dan Sikap Konsumen Terhadap Produk". Telaah Bisnis, 2. No 2, h.99-114

Balqis (2004), “ Analisis Persepsi Masyarakat Terhadap Sabun Mandi cair Di Kota Malang,” Lintasan Ekonomi, XX1 (2),h. 226-255

Chasanah, Uswatun (2003), :" Membangun Ekuitas Merek Melalui Brand Personality", Kajian Bisnis STIE Widya Wiwaha Yogyakarta, No. 29 h.99-100

Cooper,D.R and Schindler (2000)," Business Research Methods' $7^{\text {th }}$. New York : Mc-Graw Hill

Dharmmesta, B.S (1999)," Loyalitas Pelanggan : Sebuah Kajian Konseptual Sebagai Panduan Bagi Peneliti”, Journal Ekonomi Dan Bisniss Indonesia, 14, No. 3, h. 73-88

Kotler, P. (2003) Marketing Management $11^{\text {th }}$. Upper Saddle River, NJ : Prentice Hall Inc.

Kotler, P. and Keller (2006), Marketing Management $12^{\text {th }}$. Upper saddle River, NJ : Prantice Hall Inc.

Listriani, (2004), "Pengaruh Loyalitas Konsumen Terhadap Permintaan Mie Instant Merek Indomie Di Kota Yogyakarta", Tesis Program Studi Magister Manajemen Program Pasca Sarjana Universitas Gadjah Mada (Tidak Dipublikasikan)

Singarimbun, Masri dan Sofian Efendi( (1998), Metodelogi Penelitian survey, Edisi Revisi, Jakarta : :PT. Pustaka LP3ES

Tjiptono, Fandi (1996b), Manajemen Jasa, Yogyakarta : Andi Offset

Vennywatie, D. (2003), Pengaruh Persepsi Produk, Persepsi Kualitas Layanan, dan Persepsi Kewajaran Harga Terhadap Kepuasan dan Loyalitas Pelanggan, Tesis Program Studi Magister Manajemen Program Pasca Sarjana Universitas Gadjah Mada (tidak Dipublikasikan) 